\title{
NOVES INSCRIPCIONS IBÈRIQUES I ROMANES DE LESERA (la Moleta dels Frares, Forcall - Castelló)
}

En les campanyes d'excavacions realitzades a la ciutat romana de Lesera entre els anys 2001 i 2009 i en prospeccions superficials es van trobar diverses peces que presenten grafits. En aquesta nota en presentem quatre, un d'ibèric i tres de llatins, els suports dels quals són ceràmica (comuna i TSH), pedra (téssera) i metall (anell de plata $)^{1}$.

\section{INSCRIPCIONS IBÈRIQUES}

La troballa de grafits ibèrics sobre ceràmica al jaciment es coneix des de la publicació de Fletcher d'un fragment de vora de TSH trobat en superfície en una de les prospeccions prèvies a l'excavació de 1960 (Fletcher 1972: 105-106, làm. I, 1; Oliver 1978: 278-280; Siles 1985: 378, no 1719; Arasa 1987: 27; Silgo 1994: 221). Es tracta d'un grafit postcocció incomplet, on la fractura afecta el principi de text i l'extrem inferior dels quatre signes conservats, dels quals al primer li falta la part superior esquerra: ---]rabau. Per la producció sobre la qual apareix ha de datar-se en un moment avançat de la segona meitat del s. I dE, de manera que -com ja va assenyalar Siles- es tracta d'un dels casos més tardans d'ús del signari ibèric. En l'excavació de 1960, al sondeig obert en la domus situada a l'extrem nord de la plataforma superior, Pla va trobar un pondus de teler que tenia una aspa incisa en la cara superior, que pot interpretar-se com el signe ta (Arasa, 1987: 37, $\mathrm{n}^{\circ}$ 229, fig. 23). Ara presentem un altre grafit procedent d'una troballa superficial.

1) Téssera trobada en superfície per J. Carbó Pallarés -collaborador de les excavacions- el dia 8-09-2007 a l'extrem nord de la plataforma superior, a prop de l'esmentada domus, que la va donar a l'ajuntament de Forcall per a la seua Col-lecció Museogràfica. És de pedra calcària, té forma arrodonida i les seues cares no estan polides (fig. 1). Les seues dimensions són 16,1-14,7 mm d'amplària i 4,2 mm de grossària (Arasa 2009: 125, fig. 89). En una de les seues cares es distingeixen diverses línies incises molt superficialment amb traços molt fins i un poc desgastats. D'altra banda, poc menys de la meitat dreta de la pedra presenta una major porositat i desgast, potser per haver estat exposada a diferents condicions de conservació. En el costat esquerre es reconeix clarament el grafema ibèric $i$, mentre que a la dreta es veuen algunes línies molt fines i superficials que poden correspondre a un o més signes que no es poden reconèixer amb seguretat. La posició del primer en un lateral s'adiu amb la presència 


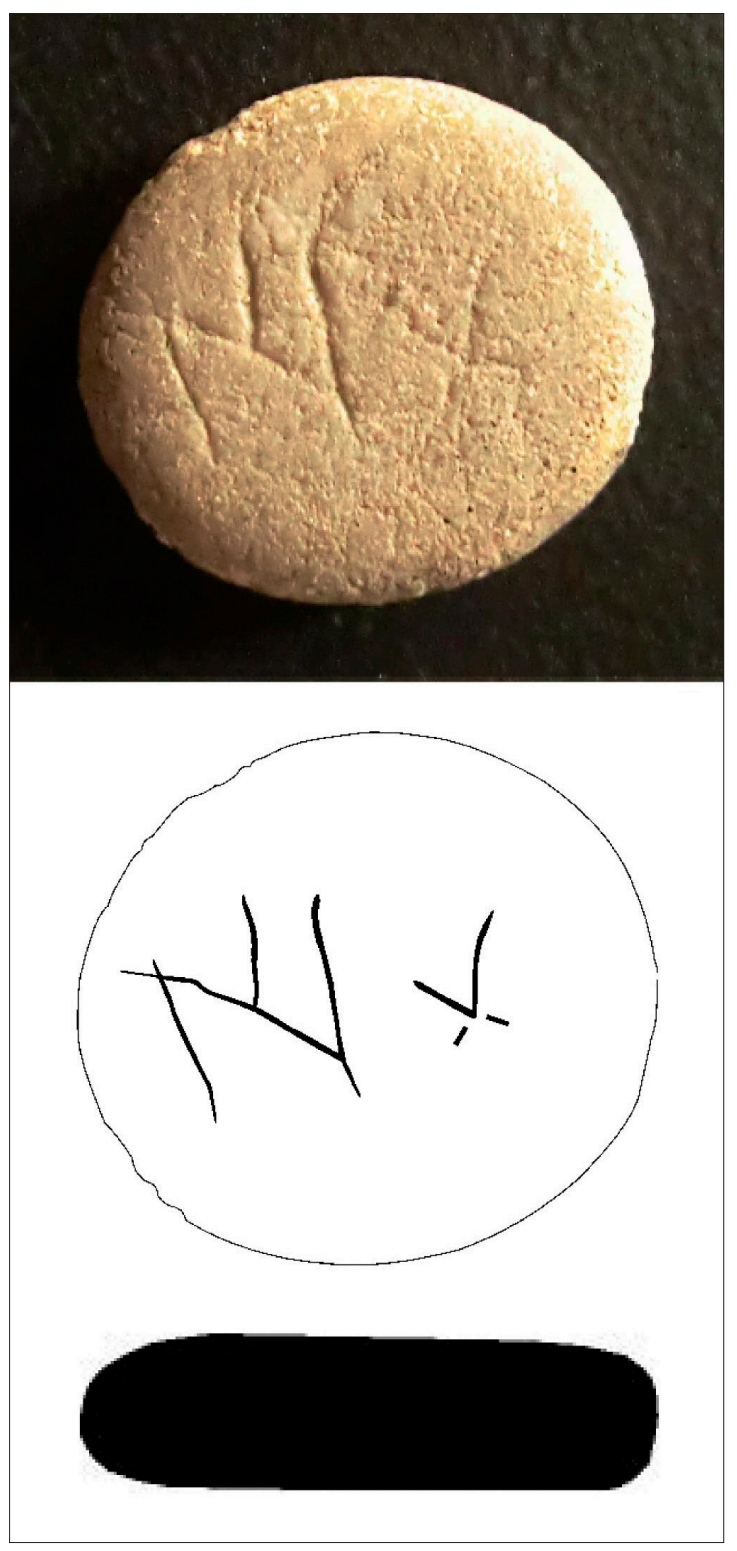

Fig. 1. Téssera amb grafit ibèric.

d'almenys un segon grafema a continuació. A la dreta i un poc desplaçats cap avall en relació amb l'anterior s'hi distingeixen dos traços que formen una $\mathrm{V}$ i sembla que es prolonguen en aquesta direcció, però sense que permeten identificar clarament un signe. Altres traços més curts que poden ser naturals fan més confusa la lectura; fins i tot podria distingir-se la traça d'una $a$ que formaria nexe amb el primer grafema. Tanmateix, si considerem l'aspa parcialment conservada com la traça més segura d'un signe, les dues opcions més probables són que es tracte de ta o be. D'aquesta manera tindríem una seqüència bisil-làbica formada per un primer signe vocàlic i un segon de caràcter sil·làbic. En la primera hipòtesi de lectura, ita apareix en el lèxic ibèric en tres ocasions (Silgo 1994: 175): Azaila (E.1.8), la Punta de la Vall d'Uixó (F.9.7) i Osseja (B.13.2). La possible presència d'un nexe ia que formaria la seqüència iata també està documentada a la Punta de la Vall d'Uixó (Silgo 1994: 171) i al Pico de los Ajos (F.20.1). Però el fet que l'encreuament dels dos traços estiga situat prou cap avall, quasi en la base de la $i$, sembla que s'adequa més amb el grafema be, la part superior del qual podria haver-se esborrat. En aquest sentit, cal destacar que el segment ibe forma part d'un element antroponímic (Untermann 1987: 302; 1990: 222): ibes, amb presència a Llíria (F.13.15), Alcoi (G.1.5) i El Cigarralejo (G.13.1), i ibeis, a Énguera (F.21.1).

\section{INSCRIPCIONS LLATINES}

Les inscripcions incises en alfabet llatí eren conegudes a la Moleta des que es va donar a conèixer el jaciment l'any 1876, quan van començar a trobar-se tésseres amb breus textos que majoritàriament van passar a formar part de la col·lecció arqueològica de la família dels propietaris amb un notable grups d'entalles (Arigó 1879: 10, làm., no 8; 1880: 5; Ferrer 1888; CIL II 62467; Mateu 1981; Arasa 1987: 22-23, làm. XXII; 2009: 122-123, fig. 87; IRPV II 85-87). Posteriorment, en el sondeig que Pla va realitzar l'any 1960 a l'esmentada domus va trobar un pivot d'àmfora Dr. 2-4 amb un grafit precocció en posició invertida que possiblement correspon a un nom abreviat: $O p(---)$ (Arasa 1987: 36, n 177 , fig. 20, làm. XX) i una téssera de pedra amb el numeral $X X V$ (Arasa 1987: 35, $\mathrm{n}^{\circ}$ 224, fig. 23, làm. XX); i en el tercer sondeig obert a l'extrem $\mathrm{N}$ de la plataforma inferior va trobar dos fragments de TSH amb esgrafiats incomplets (Arasa 1987: 46, nº 496-497, fig. 34). Algunes de les troballes que ací presentem provenen també de l'esmentada domus, que va ser totalment excavada en les campanyes realitzades entre els anys 2001 i 2005, i la darrera es va trobar en un dels sondeigs oberts en la zona on se suposa podia estar emplaçat el fòrum del municipi, en la terrassa central del sector NE de la plataforma inferior, a prop del tercer sondeig de Pla. 

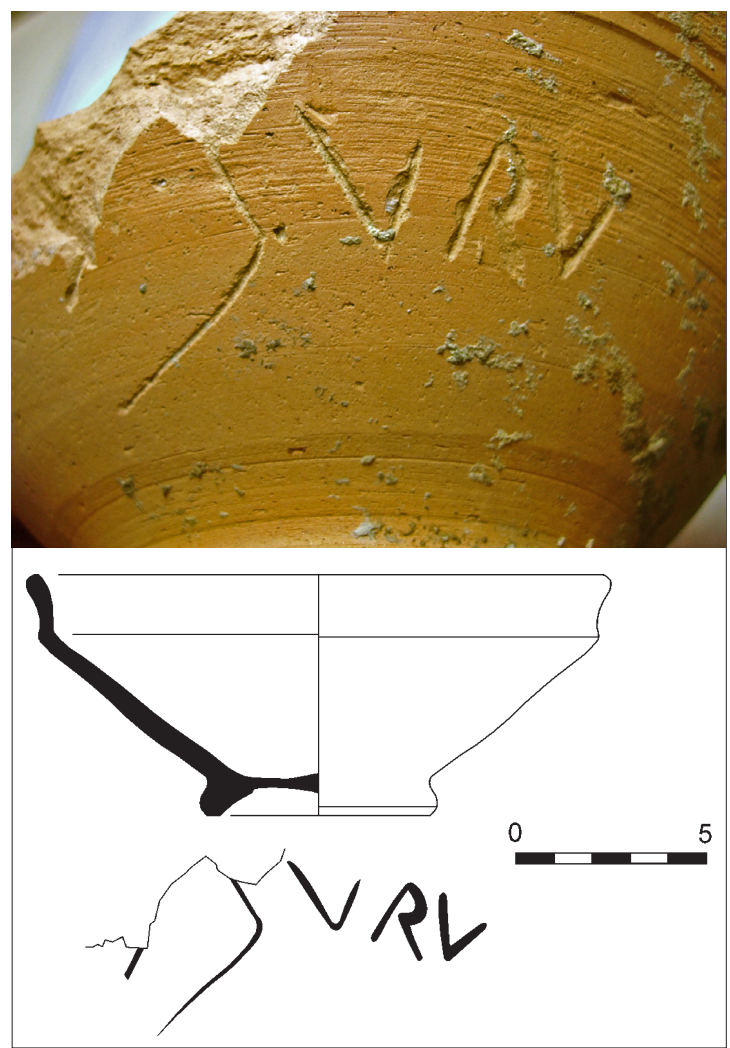

Fig. 2. Inscripció $n^{\circ} 2$ sobre un bol de ceràmica comuna.

2) Text incís sobre la superfície exterior d'un bol (catinus/catillus) de ceràmica comuna de cocció oxidant (LM-03-1037-1)2 , trobat en la campanya del 2003 de les excavacions de la citada domus (Arasa 2006: 63; 2009: 111, fig. 81). Presenta una carena marcada en el terç superior del cos que el separa de la vora còncava, amb el llavi sense diferenciar, i pertany al tipus IV.3.1.3, amb capacitat per a una hemina, que data del període flavi (Escrivà 1995: 176, fig. 8, 3). Le seues dimensions són $15,5 \mathrm{~cm}$ de diàmetre i $6,5 \mathrm{~cm}$ d'altura (fig. 2). Va aparèixer a la UE 1037 , els materials més recents de la qual poden datar-se cap al final del s. I dE. El grafit es troba incomplet en el seu inici i s'hi poden llegir tres lletres corresponents a la terminació-uru; davant es veuen dos traços que poden correspondre a altres dues lletres, dels quals el segon i més complet deu ser una $\mathrm{S}$, mentre que del primer -que normalment hauria de ser una vocal- només es veu l'extrem inferior inclinat de dreta a esquerra, de manera que la seua lectura sembla [---]+suru, que possiblement és la terminació d'un nom personal en ablatiu, quelcom no molt freqüent en aquesta
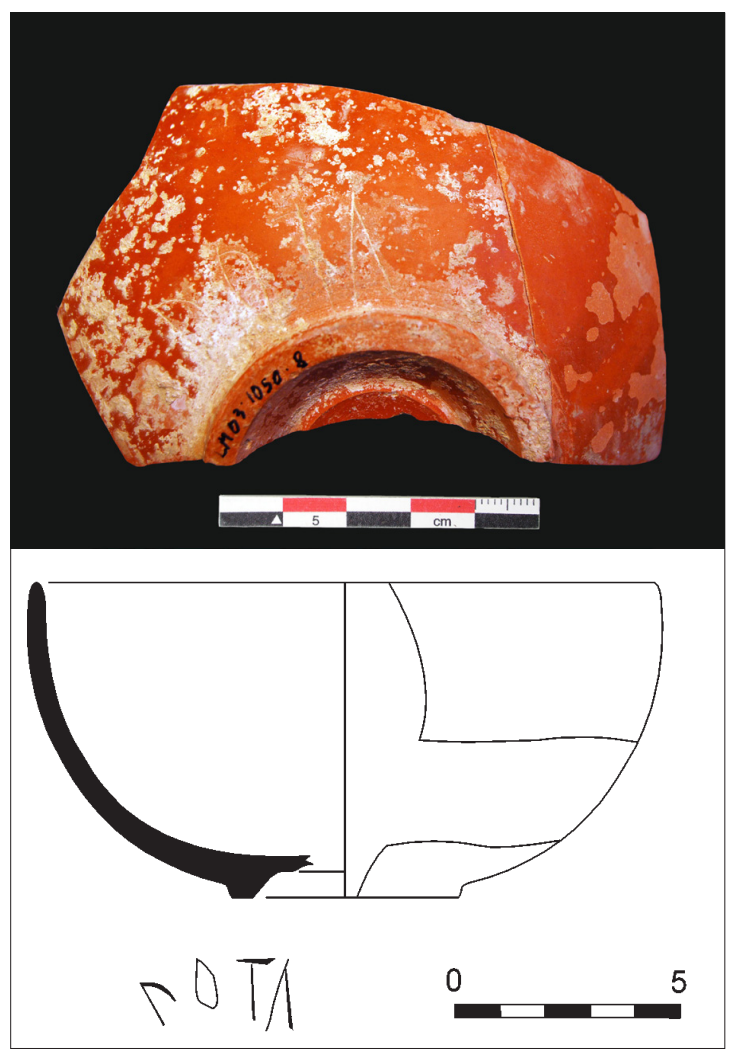

Fig. 3. Inscripció $\mathrm{n}^{\mathrm{o}} 3$ sobre un bol de TSH.

mena d'epígrafs. Quant a l'onomàstica, el cognom Surus és molt freqüent per tot l'Imperi i està documentat en sis ocasions a Hispània (Abascal 1994: 519), una de les quals a Saguntum (CIL II ${ }^{2} / 14,587$ = IRPV I 333) en el nom d'un ostiarius. Tanmateix, la presència d'un altre signe davant de la $\mathrm{S}$ fa pensar que es tracta d'un altre nom amb aquesta mateixa terminació, que podria ser Casurus, documentat a les Gàl-lies o Visurus, a Verona ${ }^{3}$; el fet que el primer signe es trobe tan incomplet impedeix decidir-se per alguna d'aquestes opcions.

3) Part d'un bol hemisfèric de TSH de la forma 8 de les produccions de Tritium Magallum (fig. 3), que es va trobar en les excavacions de la mateixa domus, també en la campanya de 2003, a la UE 1050 de l'habitació 4, que és un paquet d'enderrocs que segella la tercera fase constructiva que pot datar-se en la primera meitat del s. II dE (LM-03-1050-8). Està format per dos fragments que encaixen i corresponen a la part inferior de la paret i la base. El text es troba incís en la part inferior de la paret, al 


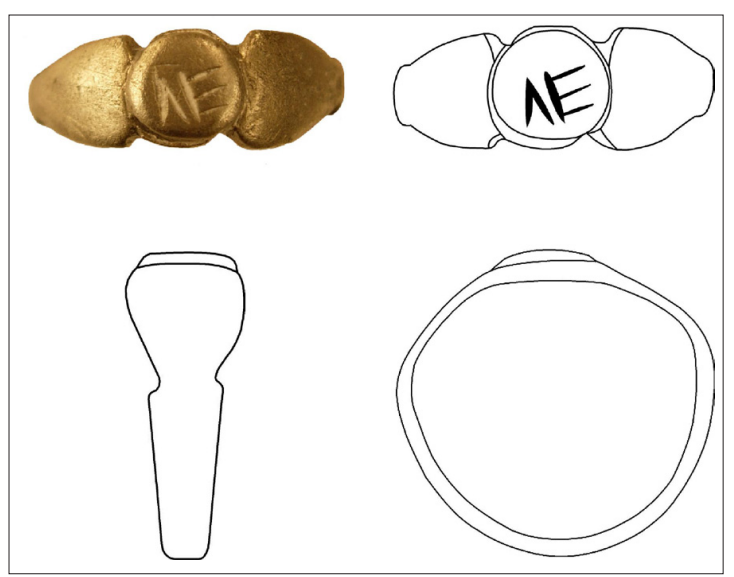

Fig. 4. Inscripció $\mathrm{n}^{\circ} 4$ sobre anell.

voltant de la base, està sencer i consta de quatre lletres ben conservades que poden llegir-se sense dificultat: Pota. Sobre el supòsit més usual que es tracte d'una marca de propietat, la primera opció és el propi cognom Pota, fins ara no documentat en les províncies hispàniques, però sí en algun cas a Àfrica (Geminia Pota, de Constantina: EDCS-13200279 = CIL VIII 7386). Tanmateix, no pot descartar-se la possibilitat que estiga abreviat i es tracte d'un cognom d'origen grec de la família de Potamius (Solin 2003, II: 1480; III: 1067-1068), que trobem en algun cas a la península (Abascal 1994: 464). Fóra més estrany que es tractara del present d'imperatiu del verb poto ('beure'), amb la traducció de 'Beu!', que seria acord amb la seua presència en una copa, però que suposaria un coneixement avançat de l'ús del llatí.

4) Anell de plata amb xató circular trobat en la campanya de 2005 a la UE 1037 del sondeig 1 de la trinxera oberta a la zona central del sector nord de la terrassa central. Es tracta d'una UE de sedimentació situada per davall del nivell agrícola, amb materials majoritàriament romans. Dimensions màximes: 17,2 mm de diàmetre exterior, 14,9 $\mathrm{mm}$ de diàmetre interior, $6 \mathrm{~mm}$ d'amplària màxima i 1,4 $\mathrm{mm}$ de grossària; el xató té 5,6 mm d'amplària i 1,7 mm de grossària (fig. 4). El reduït diàmetre interior fa pensar que estava destinat a un infant. L'anell es fa més ample cap a la part superior per tal d'abraçar el xató, que queda a major altura i diferenciat mitjançant una motlura. Pertany al tipus 3 que Guiraud va establir entre els anells gal-lo-romans, que es caracteritza justament perquè el xató es troba més alt que la línia de l'anell; s'aproxima al subtipus 3c, encara que no és exactament igual. Segons aquesta autora, el tipus 3 apareix en la segona meitat del s. II i es desenvolupa durant la major part del III (Guiraud 1989: 185, fig. 21). Presenta dues lletres incises, $A E$, que poden llegir-se sense dificultat i deuen correspondre a les inicials del nom del propietari o propietària (Arasa 2009: 125-126, fig. 90). Les inscripcions que apareixen sobre els anells corresponen normalment als noms dels seus portadors, en ocasions acompanyats d'altres expressions (Gimeno 2012: 208, $\mathrm{n}^{\circ}$ 14-15). Així, doncs, deu tractar-se del cognom del/la portador/a que per estar abreviat deixa obertes diverses possibilitats (Abascal 1994: 258-260), de les quals la més normal seria Aemilianus/- $a$, que en la forma femenina trobem a la població castellonenca de l'Alcora sobre un epígraf funerari $\left(C I L \mathrm{II}^{2} / 14,752=I R P V \mathrm{I} 535\right)$.

FERran Arasa I GIL Dept. de Prehistòria i Arqueologia Universitat de València Ferran.Arasa@uv.es

\section{NOTES}

1. He d'agrair la lectura del manuscrit i els seus enriquidors comentaris als professors J. M. Abascal (UA) i P. P. Ripollès (UV).

2. L'inventari, classificació i dibuix dels materials recuperats en les excavacions dels anys 2001-2005 portades a terme en aquesta domus els ha realitzat Esperança Huguet, a qui vull agrair la seua dedicació.

3. Casurus: EDCS-50199519 (Saintes), 50400136-7 (Auch), 52600050 (Vannes) i 53900133, 53900150, 53901011 i 53901012-3 (Montans); Visurus: EDCS-04202355 (Verona). No figuren en la segona edició del corpus de Solin-Salomies (1994).

\section{BIBLIOGRAFIA}

ABASCAL, J. M. (1994): Los nombres personales en las inscripciones latinas de Hispania, Murcia.

ARASA, F (1987): Lesera (La Moleta dels Frares, El Forcall). Estudi sobre la romanització a la comarca dels Ports, MPAC, 2, Castelló de la Plana.

ARASA, F. (2006): La ciutat romana de Lesera. Les excavacions de 2001-2005, Miscel-lània en homenatge a José Eixarch Frasno (V. M. Cardona Eixarch, coord.), Vinaròs, 53-97.

ARASA, F. (2009): La ciutat romana de Lesera, Ajuntament de Forcall, Vinaròs.

ARIGÓ, L. M. (1879): Memoria de los trabajos llevados a cabo por la Sociedad Arqueológica Valenciana durante el año 1878, Valencia. 
ARIGÓ, L. M. (1880): Memoria de los trabajos llevados a cabo por la Sociedad Arqueológica Valenciana durante el año 1879, Valencia.

CIL II = HÜBNER, E. (1892): Corpus Inscriptionum Latinarum. Inscriptiones Hispaniae Latinae. Suplementum, II, Berlín.

CIL II²/14 = ALFÖLDY, G.; MAYER, M.; STYLOW, A. U. (eds.) (1995): Corpus inscriptionum latinarum II: Inscriptiones Hispaniae latinae. Editio altera. Pars XIV: Conventus Tarraconensis. Fasciculus primus: pars meridionalis Conventus Tarraconensis (CIL II2/14), fasc. 1, Berlín.

EDCS = Epigraphik-Datenbank Clauss/Slaby: http://www.manfredclauss.de/ (2/11/2014).

ESCRIVÀ, V. (1995): Cerámica común romana en el Municipium Liria Edetanorum. Nuevas aportaciones al estudio de la cerámica de época altoimperial en la Hispania Tarraconensis, Ceràmica comuna romana d'època Alto-Imperial a la Península Ibèrica. Estat de la qüestió, Girona, 167-186.

FERRER, N. (1888): Visita a las ruinas de Bisgargis, Almanaque de "Las Provincias", Valencia, 266-269.

FLETCHER, D. (1972): Nuevas inscripciones ibéricas de la región valenciana, $A P L \mathrm{XIII}, 103-126$

GIMENO, H. (2012): Ad hominem luxuriem facta: inscripcions de Hispania en objetos de lujo. I. Anillos de oro y plata, Sylloge Epigraphica Barcinonensis X, 207-227.
GUIRAUD, H. (1989): Bagues et anneaux à l'époque romaine en Gaule, Gallia 46, 173-211.

IRPV I = CORELL, J. (2002): Inscripcions romanes del País Valencià. I. (Saguntum i el seu territori), València.

IRPV II = CORELL, J. (2005): Inscripcions romanes del País Valencià. II. 1. L'Alt Palància, Edeba, Lesera i els seus territoris. 2. Els mil-liaris del País Valencià, València.

MATEU, F. (1981): Camafeos procedentes de la estación arqueológica de la 'Moleta dels Frares', llamada también 'Mas de Liborio', del Forcall, Bisgargis 181, 5-10.

OLIVER, A. (1978): Epigrafía ibérica de la provincia de Castellón, CPAC 5, 265-291.

SILES, J. (1985): Léxico de inscripciones ibéricas, Madrid.

SOLIN, H. (20032): Die griechischen Personennamen in Rom, Berlin-New York.

SOLIN, H.; SALOMIES, O. (1994): Repertorium nominum gentilium et cognominum latinorum, Olms-Weidmann.

SILGO, L. (1994): Léxico ibérico, Valencia.

UNTERMANN, J. (1987): Repertorio antroponímico ibérico, APL XVII, 289-318.

UNTERMANN, J., (1990): Monumenta Linguarum Hispanicarum. III. Die iberischen Inschriften aus Spanien. 2. Die Inschriften, Wiesbaden. 